\title{
Commentary: Role of Tocilizumab in Hospitalized COVID-19 Patients: A Pragmatic Guide for Clinicians
}

\author{
Vijairam Selvaraj ${ }^{1,2 *}$, Anneliese Beaubrun ${ }^{1,2}$, Shenjun Zhu ${ }^{1,2}$, Kwame Dapaah-Afriyie ${ }^{1,2}$ \\ 'Division of Hospital Medicine, The Miriam Hospital, Providence, Rhode Island \\ ${ }^{2}$ Warren Alpert Medical School of Brown University, Providence, Rhode Island.
}

\section{Article Info}

Article Notes

Received: March 09, 2021

Accepted: March 19, 2021

\section{${ }^{*}$ Correspondence:}

*Vijairam Selvaraj MD, MPH, The Miriam Hospital, Warren Alpert Medical School of Brown University

Providence, RI 02906; Tel: 413-271-0421; Fax: 401-793-4047; Email: vijairam.selvaraj@lifespan.org.

(C) 2021 Selvaraj V. This article is distributed under the terms of the Creative Commons Attribution 4.0 International License.

\section{Introduction}

COVID-19 caused by severe acute respiratory syndromecoronavirus 2(SARS-CoV2) has resulted in many deaths worldwide. The pathophysiology of COVID-19 involves an initial mild viremic phase, followed by a pulmonary phase and then hyperinflammatory phase $^{1}$. The hyperinflammatory phase involves a dysregulated immune response and is associated with 'hypercytokinemia'. A recent review by Datta et al. ${ }^{2}$ suggested that several cytokines and chemokines may be involved in COVID-19 such as IL-1 $\beta$, IL-2, IL-6, IL-7, IL-8, IL-17, IL-18, IL-33, GM-CSF, monocyte chemoattractant protein-1 (MCP-1), interferon- $\gamma$, inducible protein 10 (IP-10), macrophage inflammatory protein-1 $\alpha$ (MIP-1 $\alpha$ ), tumor necrosis factor- $\alpha$ (TNF- $\alpha$ ) and transforming growth factor- $\beta$ (TGF- $\beta$ ). IL-6 plays a central role by promoting proliferation of myeloid precursor cells, growth and activation of leucocytes and synthesis of $\mathrm{C}$ reactive proteins. It also causes suppression of T-lymphocytes, dendritic cells, and macrophages, resulting in decreased ability of the immune system to clear SARS-CoV2. Our publication further elaborates on the efficacy of specific IL-6 inhibitors such as tocilizumab in COVID-19 patients based on recent randomized controlled trials (RCTs) and pragmatic guidelines for its use.

\section{Role of Tocilizumab in COVID-19}

Tocilizumab is a recombinant monoclonal antibody that is indicated for the treatment of giant cell arteritis, rheumatoid arthritis and life-threatening cytokine release syndrome induced by chimeric antigen receptor T-cells. It works by inhibiting IL-6 signaling by binding soluble IL-6R and membrane $\mathrm{IL}^{-6 \mathrm{R}^{3}}$. A meta-analysis of 6 studies revealed that mean IL-6 levels were 2.9-fold higher in patients with complicated COVID-19 than non-complicated disease ${ }^{4}$. Elevated levels of IL-6 have also been associated with increased viremia, prolonged viral shedding, progression to mechanical ventilation and death ${ }^{5-8}$. There are also genetic variants in the IL-6 pathway that predispose certain patients to have life threatening COVID-19 disease'. Tocilizumab has been shown to be effective in reducing inflammatory biomarkers in COVID-19 ${ }^{10}$.

To date, only dexamethasone therapy has shown to reduce mortality in patients with COVID-19 ${ }^{11}$. Nevertheless, in some severely ill patients, dexamethasone therapy alone might not be sufficient to manage the cytokine storm in the hyperinflammatory phase. Data surrounding the use of tocilizumab in COVID-19 has been contradictory. ${ }^{12,13}$ However, many of the trials were done in 
the early days of the pandemic prior to standardized use of dexamethasone in hospitalized COVID-19 patients $^{14,15}$. In addition, some of these trials only enrolled patients with mild disease in whom there may not be much benefit ${ }^{14,15}$. Recently, with the publication of data from REMAP-CAP ${ }^{16}$ and RECOVERY ${ }^{17}$ trials, benefit on clinical outcomes was noticed when tocilizumab was used concurrently with dexamethasone in hospitalized COVID-19 patients. In the REMAP-CAP trial, $88 \%$ of the patients received steroids with improved mortality and shortened time to improvement. Similarly, in the RECOVERY trial, $82 \%$ of the patients received dexamethasone. There was improved survival, probability of discharge from hospital alive by 28 days and reduced probability of progression to invasive mechanical ventilation. There was $6 \%$ reduction in mortality when tocilizumab was combined with dexamethasone, although no benefit was seen when given alone.

The Infectious Diseases Society of America (IDSA) guidelines conditionally suggest the use of tocilizumab in addition to standard of care rather than standard care alone among hospitalized patients with progressive severe or critical COVID-19 ${ }^{18}$. The National Institutes of Health (NIH) guidelines also recommend use of tocilizumab along with dexamethasone in hospitalized patients that have been admitted to the intensive care unit within the prior 24 hours and who require invasive mechanical ventilation, noninvasive mechanical ventilation, or high-flow nasal canula oxygen $\left(>0.4 \mathrm{FiO}_{2} / 30 \mathrm{~L} / \mathrm{min}\right.$ of oxygen flow). The guidelines also support use of tocilizumab in hospitalized patients with rapidly increasing oxygen needs and with significantly increased markers of inflammation ${ }^{19}$. Given limited availability and cost of tocilizumab, timing of initiating treatment with tocilizumab is very crucial. Mean CRP level from analyzing eight RCTs on tocilizumab in COVID-19 patients was noted to be $120 \mathrm{mg} / \mathrm{L}^{14-17}$, 20 23. The RECOVERY trial enrolled patients who were on supplemental oxygen with CRP $>75 \mathrm{mg} / \mathrm{L}$. In the REMAPCAP trial, tocilizumab was administered within 24 hours of organ support in the ICU although similar effects were observed across all the C-reactive protein subgroups. To reduce utilization of critical care resources and to improve hospital outcomes, we propose the following guidelines for use of tocilizumab (8mg/kg up to a maximum of $800 \mathrm{mg}$ ) in hospitalized COVID-19 patients:

1) Hospitalized COVID-19 patients with CRP $>75 \mathrm{mg} / \mathrm{L}$ with oxygen requirements $>15 \mathrm{~L} / \mathrm{min}$, use of bilevel positive airway pressure ventilation or mechanical ventilation within 24 hours of admission in the absence of other causes such as pulmonary edema, superimposed bacterial pneumonia, etc.

2) Hospitalized COVID-19 patients with CRP $>120 \mathrm{mg} / \mathrm{L}$ with rapidly escalating oxygen requirements, despite being on standard dexamethasone regimen for 36 to 48 hours.
The NIH guidelines ${ }^{19}$ recommend avoiding tocilizumab in patients with (1) significant immunosuppression, particularly in those with a history of recent use of other biologic immunomodulating drugs; (2) alanine transaminase $>5$ times the upper limit of normal; (3) high risk for gastrointestinal perforation; (4) an uncontrolled, serious bacterial, fungal, or non-SARS-CoV-2 viral infection; (5) absolute neutrophil count $<500$ cells $/ \mu \mathrm{L}$; or (6) platelet count $<50,000$ cells $/ \mu \mathrm{L}$. Even though randomized controlled trials reported increased incidence of neutropenia, there was no statistical difference in incidence of superimposed infections. In addition, certain patients may need to be treated with ivermectin if they are from areas where Strongyloidiasis is endemic ${ }^{24}$. Some patients may also require a second dose of tocilizumab, although there is insufficient data as to which patients will benefit the most.

\section{Conclusion}

Taken together, IL-6 inhibitors such as tocilizumab when administered with dexamethasone have shown to benefit hospitalized COVID-19 patients in terms of mortality, shortened time to recovery and reduced need for mechanical ventilation. The RECOVERY trial also demonstrated reduced rates of hemodialysis in patients that received tocilizumab. Certain limitations exist with these trials. Both RECOVERY and REMAP-CAP trails were open label, randomized controlled trials. Hence, there is a risk of performance and selection bias as the participants were not blinded. Given limited availability and cost of these drugs, many hospitals may not be able to provide this therapy. In the absence of these drugs, Janus Kinase (JAK) inhibitors such as baricitinib or higher dosage of dexamethasone as used in the CoDEX trial may be necessary ${ }^{25,26}$. Further studies could better assess the timing of tocilizumab therapy, outcomes with standardized dexamethasone use and use of other drugs such as baricitinib to inhibit novel targets such as JAK- 1 and 2.

\section{Author contributions}

VS and $\mathrm{AB}$ wrote the manuscript; all contributed to editing.

\section{Conflicts of Interest}

The authors declare that the research was conducted in the absence of any commercial or financial relationships that could be construed as a potential conflict of interest.

\section{Funding}

\section{None}

\section{References}

1. Siddiqi HK, Mehra MR. COVID-19 Illness in Native and Immunosuppressed States: A Clinical-Therapeutic Staging Proposal. The Journal of Heart and Lung Transplantation. 2020 Mar 20. https:// doi.org/10.1016/j.healun.2020.03.012 
2. Datta C, Bhattacharjee A. Cytokine Storm and Its Implication in Coronavirus Disease 2019 (COVID-19). J Clin Immunol. 2020 Sept 18.

3. Nishimoto $\mathrm{N}$, Kishimoto T. Humanized antihuman IL-6 receptor antibody, tocilizumab. Handb Exp Pharmacol. 2008; (181): 151-60. doi: 10.1007/978-3-540-73259-4_7. PMID: 18071945.

4. Coomes EA, Haghbayan H. Interleukin-6 in COVID-19: A Systematic Reviewand Meta-Analysis.medRxiv 2020:2020.2003.2030.20048058.

5. Chen X, Zhao B, Qu Y, et al. Detectable serum SARS-CoV-2 viral load (RNAaemia) is closely correlated with drastically elevated interleukin 6 (IL-6) level in critically ill COVID-19 patients. Clin Infect Dis 2020 April 17

6. Lin A, He Z-B, Zhang $\mathrm{S}$, et al. Early risk factors for the duration of SARS-CoV-2 viral positivity in COVID-19 patients. Clin Infect Dis 2020 April 27

7. Herold T, Jurinovic V, Arnreich C, et al. Elevated levels of IL- 6 and CRP predict the need for mechanical ventilation in COVID-19. J Allergy Clin Immunol 2020; 146(1): 128-136.e4.

8. Del Valle DM, Kim-Schulze S, Huang HH, et al. An inflammatory cytokine signature predicts COVID-19 severity and survival. Nat Med 2020 August 24 (Epub ahead of print).

9. Pairo-Castineira E, Clohisey S, Klaric L, et al. Genetic mechanisms of critical illness in COVID-19. Nature. 2021 Mar; 591(7848): 92-98. doi: 10.1038/s41586-020-03065-y. Epub 2020 Dec 11. PMID: 33307546.

10. Ivan Hariyanto $\mathrm{T}$, Kurniawan A. Tocilizumab administration is associated with the reduction in biomarkers of coronavirus disease 2019 infection. J Med Virol. 2021 Mar; 93(3): 1832-1836. doi: 10.1002/jmv.26698. Epub 2020 Dec 17. PMID: 33241872; PMCID: PMC7753293.

11. RECOVERY Collaborative Group, Horby P, Lim WS, et al. Dexamethasone in Hospitalized Patients with Covid-19. N Engl J Med. 2021 Feb 25;384(8):693-704. doi: 10.1056/NEJMoa2021436. Epub 2020 Jul 17. PMID: 32678530; PMCID: PMC7383595.

12. Hariyanto TI, Hardyson W, Kurniawan A. Efficacy and Safety of Tocilizumab for Coronavirus Disease 2019 (Covid-19) Patients: A Systematic Review and Meta-analysis. Drug Res (Stuttg). 2021 Jan 5. doi: 10.1055/a-1336-2371. Epub ahead of print. PMID: 33401328.

13. Khan FA, Stewart I, Fabbri L, et al. Systematic review and meta-analysis of anakinra, sarilumab, siltuximab and tocilizumab for COVID-19. Thorax. 2021 Feb 12:thoraxjnl-2020-215266. doi: 10.1136/ thoraxjnl-2020-215266. Epub ahead of print. PMID: 33579777; PMCID: PMC7886668.

14. Stone JH, Frigault MJ, Serling-Boyd NJ, et al.; BACC Bay Tocilizumab Trial Investigators. Efficacy of Tocilizumab in Patients Hospitalized with Covid-19. N Engl J Med. 2020 Dec 10;383(24):2333-2344. doi: 10.1056/NEJMoa2028836. Epub 2020 Oct 21. PMID: 33085857; PMCID: PMC7646626.

15. Salvarani C, Dolci G, Massari M, et al. RCT-TCZ-COVID-19 Study Group. Effect of Tocilizumab vs Standard Care on Clinical Worsening in Patients Hospitalized With COVID-19 Pneumonia: A Randomized Clinical Trial. JAMA Intern Med. 2021 Jan 1; 181(1): 24-31. doi: 10.1001/jamainternmed.2020.6615. PMID: 33080005; PMCID: PMC7577199.

16. REMAP-CAP Investigators, Gordon AC, Mouncey PR, et al. Interleukin-6 Receptor Antagonists in Critically Ill Patients with Covid-19. N Engl J Med. 2021 Feb 25. doi: 10.1056/NEJMoa2100433. Epub ahead of print. PMID: 33631065.

17. RECOVERY Collaborative Group, Horby PW, Pessoa-Amorim G, et al. Tocilizumab in patients admitted to hospital with COVID-19 (RECOVERY): preliminary results of a randomised, controlled, openlabel, platform trial medRxiv 2021.02.11.21249258; doi: https://doi. org/10.1101/2021.02.11.21249258

18. Infectious Diseases Society of America (IDSA) guidelines on the Treatment and Management of Patients with COVID-19. https://www. idsociety.org/practice-guideline/covid-19-guideline-treatment-andmanagement/. Accessed March 5, 2021.

19. National Institutes of Health (NIH) COVID-19 Treatment Guidelines. The COVID-19 Treatment Guidelines Panel's Statement on the Use of Tocilizumab for the Treatment of COVID-19 https://www. covid19treatmentguidelines.nih.gov/statement-on-tocilizumab/ Accessed March 5, 2021.

20. Rosas IO, Bräu N, Waters M, et al. Tocilizumab in Hospitalized Patients with Severe Covid-19 Pneumonia. N Engl J Med. 2021 Feb 25. doi: 10.1056/NEJMoa2028700. Epub ahead of print. PMID: 33631066.

21. Salama C, Han J, Yau L, et al. Tocilizumab in Patients Hospitalized with Covid-19 Pneumonia. N Engl J Med. 2021 Jan 7; 384(1): 20-30. doi: 10.1056/NEJMoa2030340. Epub 2020 Dec 17. PMID: 33332779; PMCID: PMC7781101.

22. Hermine O, Mariette X, Tharaux PL, et al. CORIMUNO-19 Collaborative Group. Effect of Tocilizumab vs Usual Care in Adults Hospitalized With COVID-19 and Moderate or Severe Pneumonia: A Randomized Clinical Trial. JAMA Intern Med. 2021 Jan 1;181(1):32-40. doi: 10.1001/ jamainternmed.2020.6820. PMID: 33080017; PMCID: PMC7577198.

23. Veiga VC, Prats JAGG, Farias DLC, et al. Coalition covid-19 Brazil VI Investigators. Effect of tocilizumab on clinical outcomes at 15 days in patients with severe or critical coronavirus disease 2019: randomised controlled trial. BMJ. 2021 Jan 20; 372: n84. doi: 10.1136/bmj.n84. PMID: 33472855; PMCID: PMC7815251.

24. Stauffer WM, Alpern JD, Walker PF. COVID-19 and dexamethasone: a potential strategy to avoid steroid-related strongyloides hyperinfection. JAMA. 2020.

25. Tomazini B, Maia I, Cavalcanti A, et al. Effect of Dexamethasone on Days Alive and Ventilator-Free in Patients With Moderate or Severe Acute Respiratory Distress Syndrome and COVID-19: The CoDEX Randomized Clinical Trial. JAMA. 2020; 324(13): 1307-1316.

26. Kalil A, Patterson T, Mehta A, et al. Baricitinib plus Remdesivir for Hospitalized Adults with Covid-19. N Engl J Med. Published online December 11, 2020. 